\title{
The Processing Nature of the N400: Evidence from Masked Priming
}

\author{
Colin Brown and Peter Hagoort
}

Max Planck Institute for Psycholinguistics

\begin{abstract}
The $\mathrm{N} 400$ is an endogenous event-related brain potential (ERP) that is sensitive to semantic processes during language comprehension. The general question we address in this paper is which aspects of the comprehension process are manifest in the N400. The focus is on the sensitivity of the N400 to the automatic process of lexical access, or to the controlled process of lexical integration. The former process is the reflex-like and effortless behavior of computing a form representation of the linguistic signal, and of mapping this representation onto corresponding entries in the mental lexicon. The latter process concerns the integration of a spoken or written word into a higher-order meaning representation of the context within which it occurs. ERPs and reaction times (RTs) were acquired to target words preceded by semantically related and unrelated prime words. The semantic relationship between a prime and its target has been shown to modulate the amplitude of the N400 to the target. This modulation can arise from lexical access processes, reflecting the automatic spread of activation between words related in meaning in the mental lexicon. Alternatively,
\end{abstract}

\section{INTRODUCTION}

In this paper we present an empirical investigation of the processing nature of the $\mathrm{N} 400$, an endogenous eventrelated brain potential (ERP) related to semantic processes during language comprehension. The question we address is whether the N400 is largely a reflection of lexical access or of lexical integration processes. Lexical access refers to the process of computing a form representation of the physical signal, and of mapping this representation onto corresponding entries in the mental lexicon. This results in the activation of a subset of entries within the lexicon, together with their associated syntactic and semantic properties. Lexical integration processes are concerned with entering the spoken or written word into a higher-order meaning representation of the entire discourse. That is, the syntactic and semantic specifications associated with an activated lexical item are matched with a representation built up and retained in working memory containing the syntactic and semantic specifications of the current context. The better the match between these lexical and contextual specifica-

the N400 effect can arise from lexical integration processes, reflecting the relative ease of meaning integration between the prime and the target. To assess the impact of automatic lexical access processes on the N400, we compared the effect of masked and unmasked presentations of a prime on the N400 to a following target. Masking prevents perceptual identification, and as such it is claimed to rule out effects from controlled processes. It therefore enables a stringent test of the possible impact of automatic lexical access processes on the N400. The RT study showed a significant semantic priming effect under both unmasked and masked presentations of the prime. The result for masked priming reflects the effect of automatic spreading of activation during the lexical access process. The ERP study showed a significant $\mathrm{N} 400$ effect for the unmasked presentation condition, but no such effect for the masked presentation condition. This indicates that the $\mathrm{N} 400$ is not a manifestation of lexical access processes, but reflects aspects of semantic integration processes.

tions, the easier the lexical integration process is. Although models of lexical processing differ in their specification of the functional architecture for word recognition, as well as in their assumptions concerning the representational content of the mental lexicon, the general division into access and integration functions is a basic underlying feature (e.g., Forster, 1989; Frauenfelder \& Tyler, 1987; Marslen-Wilson, 1989). It is at present unclear to what extent these aspects of the word recognition process are manifest in the $\mathrm{N} 400$. This is an important issue because it has implications for the kinds of psycholinguistic questions that can be addressed by means of N400 research. For instance, there is considerable debate on the time course of the word recognition process and on the issue of which sources of linguistic and nonlinguistic knowledge can affect the lexical access and integration functions (cf. Zwitserlood, 1989). An understanding of the extent to which access and integration functions are reflected in the N400 will provide valuable information on the role that the $\mathrm{N} 400$ can play in settling this debate. Such understanding, however, presupposes a more detailed picture than currently available of the 
processing characteristics of the $\mathrm{N} 400$, as well as of the kinds of linguistic information it reflects.

It is by now firmly established that the amplitude of the N400 elicited by the visual or auditory presentation of a word is modulated as a function of the degree to which the eliciting word is related to its preceding semantic context (see Kutas \& Van Petten, 1988, for a review). Research on the N400 has concentrated on both visually presented sentential contexts (e.g., Kutas \& Hillyard, 1980, 1984; Kutas, Lindamood, \& Hillyard, 1984; Kutas, Van Petten, \& Besson, 1988), and on visual or auditory single word contexts (e.g., Bentin, McCarthy, \& Wood, 1985; Boddy, 1986; Holcomb, 1988; Holcomb \& Neville, 1990; Kutas \& Hillyard, 1989; Rugg, 1985). The latter work has used lexical priming paradigms. In such paradigms, a prime word is presented prior to a target word, and the degree and nature of the informational overlap between the prime and the target are manipulated. In semantic priming - the paradigm with which we are concerned in this paper-subjects are presented with either related (e.g., table-chair) or unrelated (e.g., apple-money) pairs of words. The standard observation with respect to the $\mathrm{N} 400$ in these kinds of semantic contexts is that the maximal amplitude of the N400 elicited by targets preceded by unrelated primes is significantly larger compared to the maximal amplitude of the N400 elicited by targets preceded by related primes. This N400 effect fits well with a large number of lexical processing experiments where reaction times were measured in lexical decision and naming tasks, and where the standard finding is that unrelated targets are responded to slower and less accurately than related targets (cf. Meyer \& Schvaneveldt, 1971; Neely, 1977; see Neely, 1991, for a review of the literature on visual semantic priming).

The conceptual analysis of the semantic priming reaction time effect has evolved from the distinction between automatic and controlled processes, exemplified in the dual-process model proposed by Posner and Snyder (1975). Automatic processes are assumed to be fast, of short duration, to not require attention or awareness, and to not draw from a common pool of resources. Controlled processes are taken to be slower, to involve resource capacity, and to be under intentional control, thereby allowing the subject's expectancies and strategies to exert an effect (cf. Shiffrin \& Schneider, 1977). Within the functional framework of word recognition given above, the lexical access function can be described as an automatic process and the lexical integration function as a controlled process. That is, the process of accessing the mental lexicon and activating a relevant subset of words is taken to be reflex-like and effortless behavior, which cannot be controlled by the subject. The process of integrating the spoken or written word within the context that accompanies it is seen as a process that can be guided by the subject's awareness of the informational content of the discourse. The specific issue, then, of whether the N400 reflects lexical access or integration processes, can be seen against the background of a more general question concerning the automatic or controlled processing nature of the N400. In the present paper, we approach this issue by investigating semantic priming effects on the $\mathrm{N} 400$.

A large number of studies has investigated the mechanisms underlying semantic priming effects, and it has become clear that different aspects need to be taken into account to assess the relative contribution of automatic and controlled processes to the priming effect, in particular when specific properties of the lexical decision and naming tasks are considered (Balota \& Chumbley, 1984; De Groot, 1984; Keefe \& Neely, 1990; Neely, 1991; Neely, Keefe, \& Ross, 1989). To date the most articulated analysis of semantic priming effects is that of Neely and Keefe (1989). They argue that three different mechanisms are required to account for the full spectrum of priming effects observed in reaction time tasks. Only one of these mechanisms is claimed to be automatic; the remaining two are forms of controlled processing.

The first mechanism is the automatic spread of activation (ASA). It assumes that strong (or direct) links exist between semantically and/or associatively related nodes in the mental lexicon (cf. Collins \& Loftus, 1975). On presentation of a word, the corresponding node in the lexicon is activated, and this activation spreads along the paths in the network to nodes representing words that are related in meaning. As a consequence, the activated nodes representing related word targets need less time for subsequent processing. The processing of unrelated words is not affected, since the activation levels of their nodes in the network will not have changed. ASA has all the characteristics attributed to automatic processes.

The second mechanism is expectancy-induced priming. Subjects can generate an expectancy set on the basis of the information contained by the prime. This expectancy set consists of words that are potential targets. If the target is a member of this set it will be recognized more quickly. If it is not, recognition will be slowed down. Unlike ASA, expectancy-induced priming therefore not only facilitates the processing of expected targets, but also inhibits the processing of unexpected targets (cf. Neely, 1977). It can be influenced by instruction and by the list structure of the materials (for example, the proportion of related prime-target pairs; $\mathrm{cf}$. Keefe \& Neely, 1990). As such, expectancy-induced priming is characterized as a controlled process. However, it is debatable whether this form of priming is part of the normal comprehension process. The circumstances which bring about expectancy-induced priming are specific to the prime-target priming paradigm, and it has therefore been argued that this particular form of priming does not reflect the standard operations of the lexical access and integration functions (cf. De Groot, 1984; Neely, 1991).

The third mechanism is semantic matching, again a controlled process. Semantic matching (or "post-lexical 
coherence checking" in the terminology of De Groot, 1984) influences the results in a lexical decision task, but cannot account for priming effects obtained with a nam ing task. In a lexical decision task it is assumed that subjects match primes with targets and bias their decisions according to the result of this matching process. The detection of a relationship between primes and targets leads to a bias to respond "yes." If no relation is detected, then there is a bias to respond "no." Thus, semantic matching results in facilitation for related targets. For unrelated targets, however, semantic matching does not succeed, which induces a bias to respond "no." Therefore, the required yes response will be inhibited. Although Neely and Keefe (1989) posit that the effects of semantic matching are particularly salient in priming patterns obtained with the lexical decision task, it has been argued that matching processes play a role in everyday fluent reading situations (cf. De Groot, 1984; Hen derson, 1982; Neely, 1991).

In sum, three mechanisms are thought to underlie se mantic priming effects. In principle, each of these mech anisms could influence the N400 effect, but this will in part depend on the specific experimental situation in which the measurement is obtained, as is the case for reaction time priming effects. In particular the presence or absence of controlled processing effects is largely determined by stimulus-structure and task-related factors. With respect to the issue under investigation in the present study, namely the sensitivity of the N400 to processes of lexical access and/or integration, it is critical to investigate the N400 effect in stimulus situations where the possible impact of controlled processes has been eliminated. This provides the best test of the sensitivity of the N400 to lexical access processes. If the N400 is indeed sensitive to automatic processes during lexical processing, then experimental manipulations that emphasize or isolate the influence of ASA, should modulate the N400 effect.

Until now, very few studies have been conducted that directly address the processing nature of the $\mathrm{N} 400$, and the results are equivocal.

Boddy (1986) investigated the effects of stimulus onset asynchrony (SOA) between primes and targets on ERPS elicited in a semantic priming paradigm with a lexical decision task. Manipulating SOA is a traditional method to assess the impact of ASA, because under normal reading conditions this automatic process contributes to semantic priming effects only within a restricted temporal window of some 500 msec (De Groot, 1984; Neely, 1977; Prather \& Swinney, 1988). Boddy obtained the standard N400 effect as a function of semantic relatedness, but this effect, as well as the reaction time priming effect, was not modulated by SOA, which was varied between 200 , 600 , and $1000 \mathrm{msec}$. Although Boddy is cautious in interpreting this absence of effects due to SOA, he posits that the null result indicates that the N400 effect is due to controlled processes (although he characterizes the observed negativity - which he refers to as the N2 component-as "an automatically generated enhancement of arousal"). The absence of a differential reaction time effect for the short and long SOAs suggests that Boddy's SOA manipulation did not result in a suppression of the contribution of controlled lexical processing. Although a short SOA condition has been shown to be effective in excluding expectancy-induced priming effects (cf. Neely, 1991), it does not rule out the influence of semantic matching processes (cf. De Groot, 1984). So it remains unclear on the basis of Boddy's data whether a mixture of different priming mechanisms is reflected in the $\mathrm{N} 400$.

Holcomb (1988) assessed the relative impact of automatic and controlled processes on the N400 effect by manipulating the proportion of related wordpairs presented in a lexical decision task, in combination with an instruction to either ignore or attend to the semantic relationship within a wordpair. Manipulating the proportion of related wordpairs in a list is a standard method to assess the impact of expectancy-induced priming, and instruction is thought to contribute to this priming mechanism. His basic finding was that an N400 effect is observed for both high and low relatedness proportions, and that the effect is largest in high proportion lists. Holcomb argues that his results show that apart from controlled processes, the $\mathrm{N} 400$ also reflects automatic processes. This claim is based on the assumption that the low proportion list excluded effects due to expectancy-induced priming. However, the manipulation used by Holcomb does not exclude the other form of controlled processing, namely semantic matching. So it is not clear whether the amplitude of the N400 is actually influenced by ASA.

Finally, Kutas and Hillyard (1989) report data from a semantic priming paradigm in which the subjects' attention was focused on nonsemantic properties of the stimuli, in an attempt to assess the contribution of automatic processes to the N400. Subjects read pairs of semantically related or unrelated words, followed by a single letter. Their task was to judge whether the letter had been present in either of the preceding words. Following presentation of all the stimuli, the subjects rated the degree of relatedness within each wordpair. The EEG signal was averaged both on the basis of the subjects' ratings and on the basis of established association norms. Both analyses showed that the amplitude of the N400 was modulated by the degree of semantic relatedness, despite the fact that the subjects' task was in no way connected to the meaning aspects of the stimuli. On the basis of these results, Kutas and Hillyard hypothesize that automatic processes do manifest themselves in the N400, although they point out that they cannot exclude that subjects were in fact consciously aware of the semantic relations between the words, despite having only to perform a delayed letter search task. This is indeed critical. Because the task situation did not exclude controlled lexical processing, it cannot, therefore, be ruled out that the ob- 
served N400 effects are actually a reflection of controlled instead of automatic lexical processing.

The work discussed above does not provide a conclusive characterization of the $\mathrm{N} 400$ with respect to automatic and controlled processes, and this is explicitly pointed out by all of the researchers involved. Neither does it relate the $\mathrm{N} 400$ to processes of lexical access and integration, which has been a largely ignored issue in the literature on the $\mathrm{N} 400$. The main reason why the processing nature of the $\mathrm{N} 400$ has remained elusive is because the experiments reported so far did not sufficiently separate the effects of ASA, expectancy-induced priming, and semantic matching. This makes it difficult to assess what the relative influence of these mechanisms is in terms of the observed amplitude differences of the $\mathrm{N} 400$. We believe that a more stringent test-perhaps within the spectrum of currently available methodologies the most stringent test-of the processing nature of the N400 can be obtained by using the visual masked priming technique. We will report reaction time and ERP data from a visual semantic priming paradigm, using both masked and unmasked presentations of the prime.

The general procedure in visual masked priming is to present some form of pattern mask (e.g., hash marks, skewed parts of letters) immediately following (and sometimes preceding, cf. Forster \& Davis, 1984) a briefly presented (usually between 10 and $40 \mathrm{msec}$ ) prime word, following which an unmasked target word is presented on which some task has to be performed (e.g., lexical decision). Under appropriate viewing conditions, the masking technique prevents a stimulus from reaching conscious perception, and as such it is claimed that masking by and large rules out controlled processing (cf. Marcel, 1983).

A number of researchers have used the masking technique in semantic priming paradigms, and report significant priming effects despite the subjects' inability to perceptually identify the prime (e.g., Dagenbach, Carr, \& Wilhelmsen, 1989; Fowler, Wolford, Slade, \& Tassinary, 1981; Kemp-Wheeler \& Hill, 1988; Marcel, 1983). Such evidence has been taken as strong support for a characterization of lexical semantic priming in terms of automatic processes of spreading activation within the lexicon. At the same time, the evidence argues against the necessity of any essential role for controlled processes in bringing about a semantic priming effect.

The masking technique has been the subject of an intense methodological debate, mostly directed against the validity of the threshold setting procedures (cf. Cheesman \& Merikle, 1984, 1985; Holender, 1986). Cheesman and Merikle, for instance, distinguish subjective from objective thresholds. The former is "the detection level at which subjects claim not to be able to discriminate perceptual information at better than a chance level", whereas the latter is "the detection level at which perceptual information is actually discriminated at a chance level" (Cheesman \& Merikle, 1984, p. 391).
The claim is that masked priming only obtains at subjective thresholds, and, hence, that there is no evidence for true perception without awareness (but see KempWheeler \& Hill, 1988, who report masked priming effects using objective threshold presentation conditions). Both with subjective and objective thresholds, however, perceptual identification is excluded. Under appropriate masking conditions, subjects are totally unaware of the identity of a masked prime, as can be demonstrated both by their subjective reports and their performance on a forced-choice recognition task. Since it is assumed that perceptual identification is a prerequisite for expectancyinduced priming and semantic matching to occur, this implies that masking prevents the possible impact of both forms of controlled processing. Any remaining priming effects are thereby due only to ASA.

Our claim then is that visual masked priming enables an empirical test of the processing nature of the $\mathrm{N} 400$. In comparing masked and unmasked priming conditions, the predictions concerning the amplitude of the $\mathrm{N} 400$ to targets preceded by masked or unmasked primes are straightforward. If the $\mathrm{N} 400$ reflects in large part lexical access processes, then an $\mathrm{N} 400$ effect will be observed as a function of the semantic relation between primetarget wordpairs, under both masked and unmasked presentation of the primes. If, however, the $\mathrm{N} 400$ reflects in large part lexical integration processes, then an N400 effect will not be obtained with the masked presentation.

\section{RESULTS}

\section{RT Experiments}

The results of the unmasked and masked version of the RT study are summarized in Table 1. The unmasked version of the RT experiment resulted in a priming effect of $70 \mathrm{msec}$, which was highly significant both in a subject analysis $\left[F_{1}(1,14)=99.82\right.$, MSe $\left.=363.09, p<0.0001\right]$ and in an item analysis $\left[F_{2}(1,39)=280.83\right.$, MSe $=344.17$, $p<0.0001]$. As was expected, subjects are faster in responding to a target word when it is preceded by a semantically related word than when it is preceded by a semantically unrelated word (Meyer \& Schvaneveldt, 1971).

For the masked version of the RT experiment, subjects with a score of more than 11 out of 30 correct on the forced-choice recognition task were excluded from fur-

TABLE 1. Lexical Decision Latencies (in msec) on Word Targets in the Related and Unrelated Condition, Both in the Unmasked and the Masked Version of the Experiment

\begin{tabular}{lcc}
\hline & Unmasked Prime & Masked Prime \\
\hline Related target & 461 & 486 \\
Unrelated Target & 531 & 498 \\
Size of priming effect & 70 & 12 \\
\hline
\end{tabular}


ther statistical analyses. For this reason, four subjects were removed from the database. The remaining 11 subjects had a mean score of 7.8 items correct (range 3-11), which is chance level. For these subjects a priming effect of 12 msec was obtained which was significant in both the subject analysis $\left[F_{1}(1,10)=10.66\right.$, MSe $=79.96, p<$ $0.01]$ and the item analysis $\left[F_{2}(1,39)=5.21\right.$, MSe $=$ 595.11, $p<0.05$ ]. For 30 of the 40 items, the priming effect was sizeably smaller (that is, by at least $30 \mathrm{msec}$ ) in the masked version compared to the unmasked version. For only one item, a larger priming effect was obtained in the masked than in the unmasked version of the experiment.

To be certain that the priming effect in the masked version of the experiment could only be due to the processing of the semantics of the primes, a control experiment was performed. This experiment replicated the set up of the masked version of the RT experiment with one major change. In the control experiment the primes were removed and replaced by a $40 \mathrm{msec}$ blank screen between the forward and the backward mask. This resulted in a nonsignificant difference of $3 \mathrm{msec}$ between the related and unrelated conditions $\left[F_{1}(1,14)<1\right.$; $\left.F_{2}(1,39)<1\right]$.

In summary, both in the unmasked and in the masked version of the RT experiment significant priming effects were obtained. This demonstrates that when the presentation conditions exclude the contribution of forms of controlled processing to the priming effects, a smaller but significant priming effect still remains. The latter priming effect most likely reflects the automatic spread of activation between semantic nodes in the mental lexical (cf. Neely, 1991).

\section{ERP Experiments}

The ERP waveforms for the unmasked version of the experiment, averaged over subjects by condition and electrode, are presented in Figure 1. The ERP waveforms for the masked version are presented in Figure 2. Both figures show the whole prime-target epoch. Analyses were done on the basis of calculations of mean amplitudes in the $250-450 \mathrm{msec}$ range following target onset, relative to a baseline of $100 \mathrm{msec}$ directly preceding the target. In accordance with previously reported ERP semantic priming effects, an N400 effect was obtained in the unmasked version of the experiment for the group of 15 subjects. Averaged over all three midline electrode positions, the mean amplitude of the waveform was significantly more negative for the unrelated compared to the related condition $\left[F_{1}(1,14)=21.99, \mathrm{MSe}=12.11, p<\right.$ $0.0003]$. There was no main effect of electrode position $\left[F_{1}(2,28)<1\right]$, nor an interaction with the relatedness condition $\left[F_{1}(2,28)=1.43\right.$, MSe $\left.=1.50, p=0.25\right]$.

For the masked version 5 subjects had to be excluded
UNMASKED PRIMING

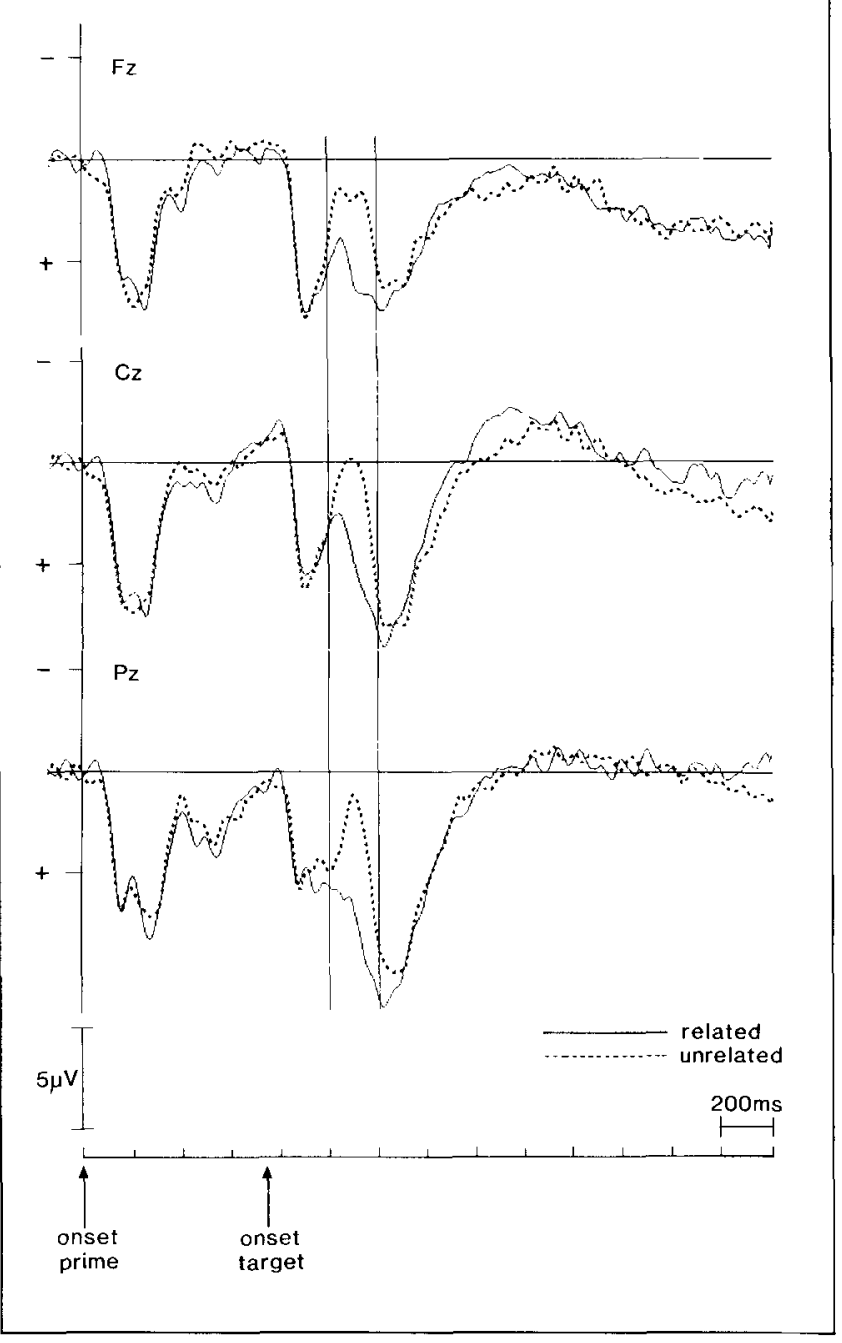

Figure 1. ERPs for the unmasked version of the experiment, by electrode position and by condition, averaged over subjects. Onsets of prime and target are marked. The area for the statistical analysis of the N400 effect lies between the two vertical lines.

on the basis of their results on the forced-choice recognition task. The remaining 15 subjects had a mean score of 7.4 items correct (range 4-11) on the forcedchoice recognition task, which again is chance level, Statistical analysis on the data of these remaining subjects showed that no $\mathrm{N} 400$ effect was observed in the masked version of the experiment $\left[F_{1}(1,14)<1\right]$. The interaction between relatedness and electrode position was also not significant $\left[F_{1}(2,28)<1\right]$.

Table 2 summarizes the mean amplitudes in the 250 $450 \mathrm{msec}$ range following target onset for each electrode position in both conditions for the unmasked and the masked version of the experiment.

In conclusion, a clear dissociation in N400 effects is observed between the unmasked and the masked version 


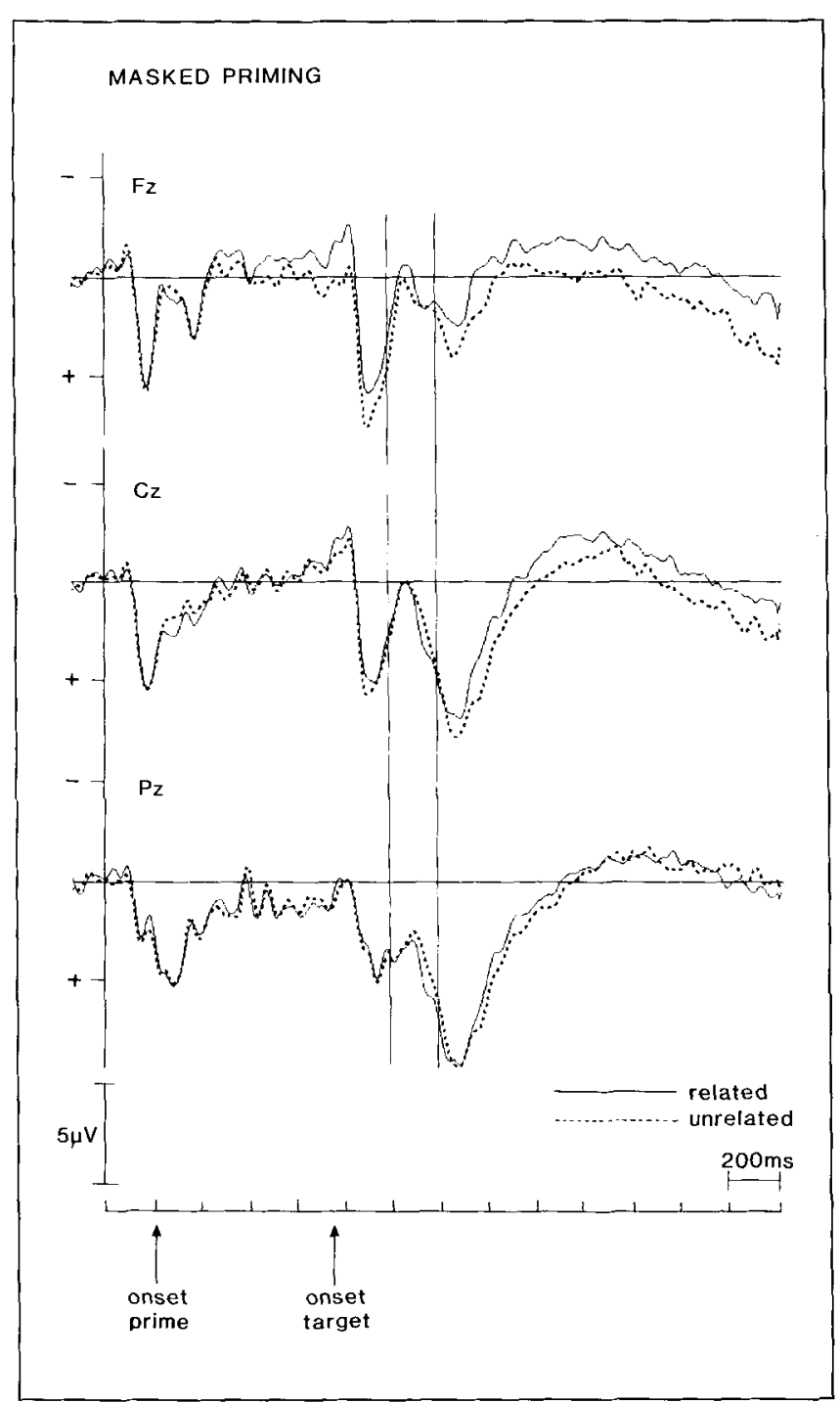

Figure 2. ERPs for the masked version of the experiment, by electrode position and by condition, averaged over subjects. Onsets of prime and target are marked. The area for the statistical analysis of the N400 effect lies between the two vertical lines.

of the experiment. N400 effects were obtained only under full viewing conditions of primes and targets. This implies that when perceptual identification of the prime is not possible, the N400 to a target word is not modulated by the meaning relations between prime and target.

\section{DISCUSSION}

To answer the question whether the $\mathrm{N} 400$ reflects mainly lexical integration processes or also processes of automatic lexical access, the critical comparison is between the results in the RT versions and the ERP versions of the experiment. Assuming that within the domain of semantic word priming ASA reflects processes that share important characteristics with lexical access in ordinary language comprehension, a presentation condition is required in which effects of ASA are isolated from those of expectancy and semantic matching. Masking of primes in a lexical decision task is such a condition (Neely, 1991). Previous research has shown that with this exper imental configuration significant RT-priming effects can be obtained. The data from our study replicate these results. Both the unmasked and the masked version of the RT experiment resulted in significant priming effects. The size of this priming effect was substantially larger in the unmasked version than in the masked version, a difference usually obtained in masked priming studies. The smaller semantic priming effects obtained with masked primes are an indication for the absence of contributions to these priming effects by expectancy and semantic matching.

Under presentation conditions identical to those in the RT versions, N400 effects were only obtained when primes were unmasked. As shown in other word priming studies (Boddy, 1986; Holcomb, 1988; Holcomb \& Neville, 1990; Kutas \& Hillyard, 1989), a reduction of the N400 amplitude occurs when a target is preceded by a semantically related prime under normal reading conditions. However, when perceptual identification of the primes was prevented by the presence of a pattern mask, a reduction of the $\mathrm{N} 400$ amplitude was no longer seen for targets preceded by semantically related primes. Thus when priming depends exclusively on ASA, no modulation of the N400 seems to result. This outcome is consistent with the view that the $\mathrm{N} 400$ is especially sensitive to lexical integration processes. Other results obtained in N400 studies further support this view. In particular the reduction of the N400 amplitude towards sentence endings for open class words (Van Petten \& Kutas, 1990) is evidence in favor of this interpretation. Increasing contextual constraints from a sentence-level representation aid in integrating incoming lexical items at later positions in the sentence, provided that their syntactic and semantic specifications are congruent with the sentential representation. This ease of lexical integration seems to be reflected in amplitude reduction for the $\mathrm{N} 400$ both in sentence and in word contexts. Additional supporting evidence for this processing account of the $\mathrm{N} 400$ has been obtained in two ERP studies on syntactic processing. In these studies a positive shift in the ERP waveforms as a result of a syntactic violation was followed by an $\mathrm{N} 400$ effect to words presented after the violation (Hagoort, Brown, \& Groothusen, in press; Osterhout \& Holcomb, 1992). Here, the violation of a syntactic constraint seems to have rendered the integration of the words following the violation more difficult compared to the integration of these very same words in the syntactically legal version of the sentences, and this processing difficulty is reflected in the N400. These contextual N400 effects are most likely not generated at the level of lexical representation, but at the level of sentential integration. At this latter level, processes have 
Table 2. Mean Amplitudes (in $\mu \mathrm{V}$ ) in the $250-450 \mathrm{msec}$ Range Following Target Onset, for $\mathrm{Fz}, \mathrm{Cz}$, and Pz in the Unrelated and Related Condition for Both the Unmasked and the Masked Version of the Experiment ${ }^{a}$

\begin{tabular}{|c|c|c|c|c|c|c|}
\hline & \multicolumn{3}{|c|}{ Unmasked Prime } & \multicolumn{3}{|c|}{ Masked Prime } \\
\hline & $F z$ & $C z$ & $P z$ & $F z$ & $C z$ & $P z$ \\
\hline Unrelated Target & 2.87 & 1.58 & 1.89 & 1.35 & 2.38 & 2.70 \\
\hline Related Target & 5.73 & 5.14 & 5.80 & 1.75 & 2.86 & 3.03 \\
\hline Difference & -2.86 & -3.56 & -3.91 & -0.40 & -0.48 & -0.33 \\
\hline
\end{tabular}

The mean amplitude values are relative to a pretarget baseline of $100 \mathrm{msec}$.

access to both the output of the form-based lexical access process and to the higher-order context representation (cf. Marslen-Wilson, 1989).

Three caveats with respect to the interpretation of the results should be made. The first concerns the signal-tonoise ratio of ERPs compared to RTs. The second concerns the registration of the $\mathrm{N} 400$ in our experiment, and the third concerns the masking technique.

It is possible that the absence of an N400 effect in the masked priming experiment does not reflect the processing nature of the $\mathrm{N} 400$. It could be claimed that the signal-to-noise $(\mathrm{S} / \mathrm{N})$ ratio of ERPs in general, and of the $\mathrm{N} 400$ in particular, is worse than the $\mathrm{S} / \mathrm{N}$ ratio for reaction times. If this is the case, then it is possible that there is an N400 effect under masked priming conditions, but this effect, in contrast to the RT effect, is too small to emerge from noise. In the absence of systematic research on the quantitative relationships between linguistic ERPand RT-priming effects, this possibility cannot be entirely excluded. However, it does not seem to be the case that N400 effects and RT effects necessarily go hand in hand, and the dissociation we have observed between N400 and RT does not stand on its own in the literature. Holcomb (1992), for instance, reports a dissociation of the effects of degrading the visual signal of a target (in a visual word-word semantic priming paradigm) on the $\mathrm{N} 400$ and on RT, with only the latter measure showing degradation effects. Furthermore, Holcomb and Anderson (personal communication, March 1992) have also found dissociations between RT and N400 effects in word-word semantic priming studies using the lexical decision task. In one auditory study they observed ERP effects starting at 150-300 $\mathrm{msec}$ and extending to 950 msec, but the RT difference between the related and unrelated condition was a nonsignificant $18 \mathrm{msec}$. In an experiment using cross-modal presentation (auditory prime, visual target) with an SOA of $200 \mathrm{msec}$, Holcomb and Anderson (1992) found a $16 \mathrm{msec}$ nonsignificant RT effect and a significant N400 effect in the $300-550 \mathrm{msec}$ time window following target onset. These studies, then, demonstrate that in the absence of significant RT effects, significant N400 effects can be observed. This weakens the plausibility of an $\mathrm{S} / \mathrm{N}$ ratio explanation of the $\mathrm{N} 400$ null effect we have observed in the ERP masked priming experiment (all the more since the absolute size of the nonsignificant RT effects found by Holcomb \& Anderson compares well with our significant $12 \mathrm{msec}$ priming effect). In conclusion, although at present there is insuffcient data on the relative $\mathrm{S} / \mathrm{N}$ ratios of $\mathrm{N} 400$ - and RTpriming effects to make strong claims about either their differences or their similarities, there is no evidence on which to maintain that the $\mathrm{N} 400$ null effect we have observed under masked priming conditions is not in fact a reflection of the fundamental processing nature of the N400.

The second caveat relates to the fact that in the experiments reported in this paper only three midline sites were recorded. It cannot, therefore, be ruled out that small N400 effects could have been observed at lateral sites, especially at right posterior sites where the N400 is claimed to be more pronounced in the case of visual presentation. However, ERP studies presenting words or sentences in the visual modality often show centro-parietal midline effects that are not less pronounced than the lateral posterior effects (e.g., see Kutas \& Hillyard, 1983). Moreover, a study in which lateral sites were recorded also failed to find $\mathrm{N} 400$ effects under masked priming conditions (Neville, Pratarelli, \& Forster, 1989). So, although the restricted EEG configuration leaves open the principled possibility of N400 effects at unrecorded sites, this outcome does not seem very likely.

The final caveat concerns the masking technique. Two recent papers on masked priming (Carr \& Dagenbach, 1990; Dagenbach et al., 1989) report that semantic facilitation obtained with masked primes could be turned into inhibition as a result of a different threshold judgment procedure preceding the lexical decision task. This, the authors argue, seems to represent a "conscious" influence on "unconscious" processing. As such it might constrain the validity of the assumption that masking excludes all forms of controlled processing. Although the results of Carr and Dagenbach (1990) and Dagenbach et al. (1989) are intriguing, it is not easy to interpret them in terms of the distinction between automatic and controlled processing. It is also unclear how the centersurround attentional mechanism that Carr and Dagen- 
bach (1990) propose by way of an alternative to dualprocess models like those of Posner and Snyder (1975) and Neely (1977) can account for the vast amount of empirical results in the word priming literature that seems to support the distinction between ASA and controlled priming mechanisms (Neely, 1991). Therefore, we still believe it is a valid assumption that the strongest evidence for ASA is priming effects obtained in a masked priming paradigm (cf. Neely, 1991). Moreover, the dissociation between RT and ERP effects in the masked priming version of our experiment is consistent with this assumption. If controlled processing had influenced the priming results under the masking conditions that we used, then the absence of an N400 effect remains unexplained.

On the basis of a clear dissociation between the pattern of results for the reaction times and the N400, we have concluded that the $\mathrm{N} 400$ is mainly sensitive to processes of lexical integration. This conclusion should be tested in further studies on the processing characteristics of the $\mathrm{N} 400$. One aspect that we are currently trying to clarify is whether the $\mathrm{N} 400$ is sensitive to both expectancy and semantic matching or only to the latter priming mechanism. Another issue under investigation is whether similar N400 effects are obtained in a reading-only situation, compared to the situation with lexical decision as an additional task. This addresses the question of whether controlled processes in semantic priming studies are induced by the task situation or arise independently of tasks other than the natural one, namely reading. In our view ERP research has a major role to play in answering this question, which is a central issue in current debates on the nature of semantic priming. Finally, research on lexical integration processes-one of the more difficult and neglected areas in language comprehension research-stands to benefit greatly from incorporating a sensitive and uncontaminated measure of these processes into its experimental program. The present results indicate that the $\mathrm{N} 400$ might provide such a measure.

\section{METHODS}

\section{Subjects}

Forty-five young subjects between 18 and 29 years old from the MPI subject pool participated in the three RT experiments, 15 in the unmasked RT experiment, 15 in the masked RT experiment, and 15 in the control experiment.

Another group of 35 subjects in the same age range participated in the two ERP experiments, 15 in the unmasked version and 20 in the masked version.

All subjects were native speakers of Dutch, had normal or corrected to normal vision, and were paid for participation in the experiments. All subjects were right handed according to self-report.

\section{Stimuli}

The stimuli consisted of a series of $\mathbf{1 6 0}$ prime-target pairs. Half of these pairs had a nonword target, half had a Dutch word as target. The word pairs consisted either of associatively related words (e.g., "peace-war"), or of words that were unrelated in meaning (e.g., "star-hour"). Half of the 80 target words was preceded by a related word prime and the other half by an unrelated word prime

The construction of the critical prime-target pairs was done according to the following procedure. A set of 84 word pairs with a related target and 84 word pairs with an unrelated target were constructed. The word targets of these two sets were matched in number of letters and in frequency. To establish word frequencies, Dutch frequency norms (Uit den Boogaart, 1975) based on a corpus of 720,000 words were used. The total set of 168 target words was supplemented by a set of 168 legal nonwords that were constructed in accordance with the phonotactic rules of Dutch, and that were matched in length with the word targets. These words and nonwords were presented in a target isolation pretest to a group of 20 subjects. Words and nonwords were visually presented in a randomized sequence to 10 subjects and in the reverse order to another group of 10 subjects. Subjects had to make a speeded lexical decision on the targets by pushing a YES button as quickly as possible when the target was a word, and a NO button when the target was not a word in Dutch. The RTs to word targets obtained in this way were used to match the set of related and unrelated targets on overall absolute RT. Each related target was matched with an unrelated target on the basis of the criterion that their RTs should not differ more than 4 msec.

This matching procedure resulted in a set of 40 word pairs with related targets, 40 word pairs with unrelated targets, and 80 legal nonwords for the prime-target pairs in the nonword condition. Both primes and targets ranged in length from 3 to 8 letters. In addition to the critical prime-target pairs, a set of 28 practice items and a set of 14 startup items were constructed.

To establish whether our masking procedure was effecrive in preventing the perceptual identification of masked primes, we constructed a forced-choice recognition test. For this test a set of 30 words was selected, matched in length and frequency with the mean values of the primes for the critical word target items of the experiment. These 30 items were presented under exactly the same masking conditions as the primes in the masked RT and ERP experiments. For each of the words three alternatives were selected for the forced-choice recognition task. The three alternatives had exactly the same number of letters as the target word, but overlapped minimally in their word forms. This meant that for most items identifying one or two letters at the appropriate position in the masked word would already be 
enough to choose the correct alternative out of the four possible responses. This led to a conservative test of the subjects' ability to perceptually identify lexical items under the masking conditions that were used in this study (cf. Cheesman \& Merikle, 1984). Given that all forms of controlled semantic priming presuppose the perceptual identification of the prime (cf. Neely, 1991), priming effects shown by subjects with a score on the forcedchoice task which is not different from chance, are assumed to be due to automatic spread of activation only.

\section{Procedures}

The stimuli were generated and controlled by a Miro GD laboratory computer and were centrally presented in a $8 \mathrm{~cm}$ by $2 \mathrm{~cm}$ window on a high-resolution PC-monitor which was covered by a black shield. Primes were presented in lowercase letters, and targets in uppercase letters. The unmasked version of the experiments consisted of the presentation of the primes for $240 \mathrm{msec}$, an interstimulus interval (ISI) of $500 \mathrm{msec}$, followed by the targets that were presented for $200 \mathrm{msec}$. A trial in the masked version began with the presentation of a forward mask consisting of a row of 8 hash marks. The size of this pattern mask matched that of the longest prime ( 8 letters). The forward mask was presented for $200 \mathrm{msec}$, following which the prime was flashed on the screen for a period of $40 \mathrm{msec}$. After the presentation of the prime a backward mask, again consisting of 8 hash marks, was presented for another 200 msec. This mask was followed by an ISI of $500 \mathrm{msec}$, on which the target was presented for $200 \mathrm{msec}$. In this way the stimulus onset asynchrony (SOA) between primes and targets was kept identical in all conditions. The interval between trials was $3 \mathrm{sec}$.

All subjects were tested individually in a dimly illuminated, sound-attenuating booth. In the masked version the experiment started with the forced-choice recognition task. Subjects were told that words would appear very briefly in the window on the screen, in between a row of hash marks. They were asked to look very carefully, and to try to see as much of the words as possible. After each item subjects had to choose one of four alternatives in a written multiple choice test. The task was self-paced. After writing down their response, subjects pushed a button that started the presentation of the next item.

After the forced-choice recognition task (in the masked version) or at the beginning of the test session (in the unmasked version) subjects were told that they would see a series of two letter strings, both clearly visible (in the unmasked version) or with the first one difficult to see (in the masked version). In addition, they were told that in some cases the second letter string formed a common word of Dutch, whereas in other cases the second letter string did not exist as a word in the Dutch language. They were required to indicate whether the second letter string was a word or not by pressing the
YES button on the response keyboard with their right index finger for words, and the NO button with their left index finger for nonwords. In the RT versions of the experiment subjects were asked to respond as quickly as possible. In the ERP versions subjects were instructed to delay their response to well after the second letter string was presented. Both response times and response codes were stored directly with the aid of the computer. The illumination conditions, and the subject's distance and position relative to the screen were kept constant among RT and ERP versions. Before the semantic priming experiment began, the set of 28 practice stimuli was presented to familiarize subjects with the procedure. No feedback concerning correctness of response was given to the subjects.

\section{EEG Recording}

The EEG was recorded with $\mathrm{Ag} / \mathrm{AgCl}$ electrodes from midline frontal $(\mathrm{Fz})$, central $(\mathrm{Cz})$, and parietal $\left(\mathrm{Pz}_{\mathrm{Z}}\right)$ sites as defined by the International 10-20 system (Jasper, 1958). Vertical and horizontal eye movements were recorded via electrodes that were placed below and at the outer canthus of the right eye. Both scalp and EOG electrodes were referenced to the left mastoid. The EEG was amplified by Nihon Kohden AB-601G bioelectric amplifiers with a $\mathrm{Hi}$-cut of $30 \mathrm{~Hz}$ and a time constant of $2 \mathrm{sec}$. The EEG was digitized on-line with a sampling frequency of $200 \mathrm{~Hz}$. Sampling started $150 \mathrm{msec}$ before onset of the prime, with a total sampling epoch of 3000 msec per trial. Data were stored along with condition codes for subsequent off-line averaging. Trials with excessive eye movement or muscle artifacts were rejected (13\% for the unmasked priming, and $11 \%$ for the masked priming experiment).

\section{Data Analysis}

\section{Analyses RT Data}

Statistical analyses were done on the latency data of the critical word target trials. Before the analyses on the latency data, errors and values below $200 \mathrm{msec}$ or above $850 \mathrm{msec}$ were replaced by the subject's mean latency in the relevant condition. A total of $3.8 \%$ of the values in the unmasked version, and $2.2 \%$ in the masked version was replaced by the mean. Repeated measures analyses of variance (ANOVA) were performed with experimental condition as the within-subject factor and subjects or items as random factors. Due to the low number of errors in all RT versions of the experiment (between $3.6 \%$ in the unmasked RT version and $1.9 \%$ in the masked version), the interpretation of the results is based only on statistical analyses of the latency data. 
Average waveforms were computed for each subject over the trials in the related and the unrelated condition. Analyses were done on the basis of calculations of mean amplitudes in the $250-450 \mathrm{msec}$ range following target onset. These calculations were done separately for each of the three midline electrode positions relative to a baseline of $100 \mathrm{msec}$ before target onset. The resulting values were entered into an ANOVA, with experimental condition (related/unrelated) and electrode site (Fz, Cz, $\mathrm{Pz}$ ) as within-subject factors.

\section{Acknowledgments}

We thank Tamara Swaab for her assistance during all phases of the research reported here, and Johan Weustink for technical support. We are indebted to Phil Holcomb and Jane Anderson for their permission to refer to some of their work in progress. Mireille Besson, Marta Kutas, and two anonymous reviewers gave valuable comments on an earlier version of the manuscript. This research was supported by Grant 560-256-039 from the Netherlands Organization for Scientific Research. Both authors contributed equally to the research reported here, and the order of authorship is arbitrary.

Reprint requests should be sent to Colin Brown, Max Planck Institute for Psycholinguistics, P.O. Box 310, NL-6500 AH Nijmegen, The Netherlands.

\section{REFERENCES}

Balota, D. A., \& Chumbley, J. I. (1984). Are lexical decisions a good measure of lexical access? The role of word frequency in the neglected decision stage. Joumal of Experimental Psychology: Human Perception and Performance, 10, 340-357.

Bentin, S., McCarthy, G., \& Wood, C. C. (1985). Event-related potentials associated with semantic priming. Electroencephalography \& Clinical Neuropbysiology, 60, 343-355.

Boddy, J. (1986). Event-related potentials in chronometric analysis of primed word recognition with different stimulus onset asynchronies. Psychophysiology, 23, 232-245.

Carr, T. H., \& Dagenbach, D. (1990). Semantic priming and repetition priming from masked words: Evidence for a center-surround attentional mechanism in perceptual recognition. Joumal of Experimental Psychology: Learning, Memory, and Cognition, 16, 341-350.

Cheesman, J., \& Merikle, P. M. (1984). Priming with and without awareness. Perception and Psychophysics, 36, 387-395.

Cheesman, J., \& Merikle, P. M. (1985). Word recognition and consciousness. In D. Besner, T. G. Waller, \& G. E. MacKinnon (Eds.), Reading research: Advances in theory and practice (Vol. 5). New York: Academic Press.

Collins, A. M., \& Loftus, E. F. (1975). A spreading-activation theory of semantic processing. Psychological Review, 82, 407-428

Dagenbach, D., Carr, T. H., \& Wilhelmsen, A. (1989). Taskinduced strategies and near-threshold priming: Conscious effects on unconscious perception. Journal of Memory and Language, 28, 412-443.

De Groot, A. M. B. (1984). Primed lexical decision: Combined effects of the proportion of related prime-target pairs and the stimulus-onset asynchrony of prime and target. The
280.

Forster, K. I. (1989). Basic issues in lexical processing. In W. D. Marslen-Wilson (Ed.), Lexical representation and process. Cambridge, MA: MIT Press.

Forster, K. I., \& Davis, C. (1984). Repetition priming and frequency attenuation in lexical access. Journal of Experimental Psychology: Learning, Memory, and Cognition, 10, 680698.

Fowler, C. A., Wolford, G., Slade, R., \& Tassinary, L. (1981). Lexical access with and without awareness. Journal of $E x$ perimental Psychology: General, 110, 341-362.

Frauenfelder, U. H., \& Tyler, L. K. (1987). The process of spoken word recognition: An introduction. Cognition, 25, 120.

Hagoort, P., Brown, C. M., \& Groothusen, J. (1992). The Syntactic Positive Shift as an ERP-measure of syntactic processing. In press.

Henderson, L. (1982). Orthography and word recognition in reading. London: Academic Press.

Holcomb, P. J. (1988). Automatic and attentional processing: An event-related brain potential analysis of semantic priming. Brain and Language, 35, 66-85.

Holcomb, P. J. (1992). Semantic priming and stimulus degra dation: Implications for the role of the N400 in language processing. Psychopbysiology, in press.

Holcomb, P. J., \& Anderson, J. (1992). Cross-modal semantic priming: A time-course analysis using event-related brain potentials. Submitted for publication.

Holcomb, P. J., \& Neville, H. J. (1990). Auditory and visual semantic priming in lexical decision: A comparison using event-related brain potentials. Language and Cognitive Processes, 5, 281-312.

Holender, D. (1986). Semantic activation without conscious identification in dichotic listening, parafoveal vision, and visual masking: A survey and appraisal. Bebavioral and Brain Sciences, 9, 1-23

Jasper, H. H. (1958). The ten-twenty electrode system of the International Federation. Electroencephalography \& Clinical Neurophysiology, 10, 371-375.

Keefe, D. E., \& Neely, J. H. (1990). Semantic priming in the pronunciation task: The role of prospective prime-generated expectancies. Memory \& Cognition, 18, 289-298

Kemp-Wheeler, S. M., \& Hill, A. B. (1988). Semantic priming without awareness: Some methodological considerations and replications. The Quarterly Journal of Experimental Psychology, 40A, 671-692.

Kutas, M., \& Hillyard, S. A. (1980). Reading senseless sentences: Brain potentials reflect semantic incongruity. Science, 207, 203-205.

Kutas, M., \& Hillyard, S. A. (1983). Event-related brain potentials to grammatical errors and semantic anomalies. Memory \& Cognition, 11, 539-550.

Kutas, M., \& Hillyard, S. A. (1984). Brain potentials during reading reflect word expectancy and semantic association. Nature (London), 307, 161-163.

Kutas, M., \& Hillyard, S. A. (1989). An electrophysiological probe of incidental semantic association. Joumal of Cognitive Neuroscience, 1, 38-49.

Kutas, M., Lindamood, T., \& Hillyard, S. A. (1984). Word expectancy and event-related potentials during sentence processing. In S. Kornblum \& J. Requin (Eds.), Preparatory states and processes. Hillsdale, NJ: Lawrence Erlbaum.

Kutas, M., \& Van Petten, C. (1988). Event-related brain potential studies of language. In P. K. Ackles, J. R. Jennings, \& M. G. H. Coles (Eds.) Adwances in psychophysiology (Vol. 3 ). Greenwich, CT: JAI Press.

Kutas, M., Van Petten, C., \& Besson, M. (1988). Event-related 
potential asymmetries during the reading of sentences. Electroencephalography \& Clinical Neurophysiology, 69, 218-233.

Marcel, A. J. (1983). Conscious and unconscious perception: Experiments on visual masking and word recognition. Cognitive Psychology, 15, 197-237.

Marslen-Wilson, W. D. (1989). Access and integration: Projecting sound onto meaning. In W. D. Marslen-Wilson (Ed.), Lexical representation and process. Cambridge, MA: MIT Press.

Meyer, D. E., \& Schvaneveldt, R. W. (1971). Facilitation in recognizing pairs of words: Evidence of a dependence between retrieval operations. Joumal of Experimental Psychology, 90, 227-234.

Neely, J. H. (1977). Semantic priming and retrieval from lexical memory: Roles of inhibitionless spreading activation and limited-capacity attention. Journal of Experimental Psycbology: General, 106, 226-254

Neely, J. H. (1991). Semantic priming effects in visual word recognition: A selective review of current findings and theories. In D. Besner \& G. Humphreys (Eds.), Basic processes in reading: Visual word recognition. Hillsdale, NJ: Lawrence Erlbaum.

Neely, J. H., \& Keefe, D. E. (1989). Semantic context effects on visual word processing: A hybrid prospective/retrospective processing theory. In G. H. Bower (Ed.), The psychology of learning and motivation: Advances in research and theory (Vol. 24). New York: Academic Press.

Neely, J. H., Keefe, D. E., \& Ross, K. L. (1989). Semantic priming in the lexical decision task: Roles of prospective primegenerated expectancies and retrospective semantic matching. Joumal of Experimental Psycbology: Learning, Memory, and Cognition, 15, 1003-1019.
Neville, H. J., Pratarelli, M. E., \& Forster, K. I. (1989). Distinct neural systems for lexical and episodic representations of words. Society for Neuroscience, Abstract.

Osterhout, L., \& Holcomb, P. J. (1992). Event-related brain potentials elicited by syntactic anomaly. Joumal of Memory and Language, in press.

Posner, M. I., \& Snyder, C. R. R. (1975). Attention and cognitive control. In R. L. Solso (Ed.), Information processing and cognition: The Loyola symposium. Hillsdale, NJ: Lawrence Erlbaum.

Prather, P. A., \& Swinney, D. A. (1988). Lexical processing and ambiguity resolution: An autonomous process in an interactive box. In S. L. Small, G. W. Cottrell, \& M. K. Tanenhaus (Eds.), Lexical ambiguity resolution: Perspectives from $p s y$ cholinguistics, neuropsychology and artificial intelligence. San Mateo, CA: Morgan Kaufmann.

Rugg, M. D. (1985). The effects of semantic priming and word repetition on event-related potentials. Psychopbysiology, 22, 642-647.

Shiffrin, R. M., \& Schneider, W. (1977). Controlled and automatic human information processing: II. Perceptual learning, automatic attending, and a general theory. Psychological Review, 84, 127-190.

Uit den Boogaart, P. C. (1975). Woordfrequenties in geschreven en gesproken Nederlands. Oosthoek: Scheltema \& Holkema.

Van Petten, C., \& Kutas, M. (1990). Interactions between sen tence context and word frequency in event-related brain potentials. Memory \& Cognition, 18, 380-393.

Zwitserlood, P. (1989). The locus of the effects of sententialsemantic context in spoken-word processing. Cognition, $32,25-64$. 